\title{
CONTRIBUIÇÕES DO CURSO ONLINE DE ESPANHOL-PORTUGUÊS PARA INTERCÂMBIO (CEPI) NA FORMAÇÃO DE PROFESSORES DE PORTUGUÊS COMO LÍNGUA ADICIONAL
}

\author{
CONTRIBUCIONES DEL CURSO ONLINE DE ESPAÑOL-PORTUGUÉS \\ PARA INTERCAMBIO (CEPI) EN LA FORMACIÓN DE PROFESORES DE \\ PORTUGUÉS COMO LENGUA ADICIONAL
}

CONTRIBUTIONS FROM CEPI (SPANISH-PORTUGUESE ONLINE COURSE FOR EXCHANGE) TO PORTUGUESE AS AN ADDITIONAL LANGUAGE TEACHER EDUCATION

\author{
Gabriela da Silva BULLA ${ }^{1}$ \\ Kétina Allen da Silva TIMBONI ${ }^{2}$ \\ Mariana BULEGON ${ }^{3}$ \\ Raquel Horvath de ANDRADE ${ }^{4}$
}

RESUMO: Este trabalho discute a formação de professores realizada no Curso online de Espanhol-Português para Intercâmbio (CEPI), vinculado ao Programa de Português para Estrangeiros (PPE), da Universidade Federal do Rio Grande do Sul (UFRGS). Para tanto, analisamos dados gerados na $10^{a}$ edição do CEPI UFRGS, que teve como professoras duas graduandas em Letras; uma tutora - Mestranda em Linguística Aplicada - e uma orientadora - Docente do curso de Letras da UFRGS. Explicitamos como o CEPI pode ser um espaço online de formação de professores, visando à construção de comunidades colaborativas de aprendizagem de português e do fazer docente.

PALAVRAS-CHAVE: Formação de Professores; Português para Intercâmbio; Educação a Distância.

RESUMEN: El trabajo discute la formación de profesores que se ha realizado en el Curso online de Español-Portugués para Intercambio (CEPI), vinculado al Programa de Portugués para Extranjeros (PPE) de la Universidad Federal de Rio Grande do Sul (UFRGS). Para eso, analizamos a los datos generados en la $10^{a}$ edición de CEPI UFRGS, que tuvo como profesoras dos estudiantes de grado en Letras de la UFRGS;

${ }^{1}$ Universidade Federal do Rio Grande do Sul (UFRGS), Porto Alegre - RS - Brasil. Professora Adjunta de Português como Língua Adicional no Departamento de Letras Clássicas e Vernáculas e Programa de Pós-Graduação em Letras. Doutora em Linguística Aplicada. ORCID: <https://orcid.org/0000-00027091-4794>. E-maill: gsbulla@gmail.com

2 Mestre em Linguística Aplicada pelo Programa de Pós-Graduação em Letras UFRGS. ORCID: <https://orcid.org/0000-0003-1246-8770>. E-mail: ketimboni@ gmail.com

${ }^{3}$ Universidade Federal do Rio Grande do Sul (UFRGS), Porto Alegre - RS - Brasil. Mestranda em Linguística Aplicada pelo Programa de Pós-Graduação em Letras. OCRID: <https://orcid.org//00000002-1064-1691>. E-mail: bulegonm@gmail.com

${ }^{4}$ Universidade Federal do Rio Grande do Sul (UFRGS), Porto Alegre - RS - Brasil. Graduanda em Letras - Português e Inglês. ORCID: <https://orcid.org/0000-0001-8137-6760>. E-mail: rqlhorvath@gmail.com 
una tutora - Estudiante de Maestría en Lingüística Aplicada - y una orientadora Maestra de la carrera de Letras de la UFRGS. Explicitamos cómo CEPI puede ser un espacio online de formación de profesores, teniendo en mente la construcción de comunidades colaborativas de aprendizaje de portugués y del hacerse profesor.

PALABRAS CLAVE: Formación de profesorado; Portugués para Intercambio; Educación a distancia.

ABSTRACT: This paper discusses the training of teachers carried out in the Online Spanish-Portuguese Course for Exchange (CEPI), linked to the Portuguese for Foreigners Program (PPE), at Federal University of Rio Grande do Sul (UFRGS). To do so, we analyzed data generated in the 10th edition of CEPI UFRGS, which had two teachers taking a degree in Languages; a tutor taking a master degree in Applied Linguistics; and a Lecturer in the course of Languages of UFRGS as the advisor. We explain how CEPI can be an online space for teacher training, aiming at the construction of collaborative communities to learn Portuguese and to learn about the practice of teaching.

KEYWORDS: Teacher training; Portuguese for exchange; Distance Education.

\section{Introdução}

Neste trabalho, discutimos como o Curso online de Espanhol-Português para Intercâmbio (CEPI) contribui para a formação de professores de Português como Língua Adicional (PLA) no Programa de Português para Estrangeiros (PPE) da Universidade Federal do Rio Grande do Sul (UFRGS). A partir da análise de dados de interação escrita em diferentes ambientes digitais, demonstramos a articulação entre a vivência docente como professores do curso online e espaços de formação com orientação pedagógica.

O CEPI é um curso inteiramente online que contabiliza entre 30 e 50 horas totais, divididas entre 5 a 7 semanas. É implementado via Moodle, grupo privado do Facebook, Google Drive e Hangouts, sendo que Messenger ou Whatsapp também começaram a ser utilizados nas últimas edições por demanda dos alunos (o Facebook foi incorporado ao CEPI também por sugestão dos alunos na segunda edição, em junho de 2011, conforme discutido em Schlatter et al, 2012). Como os materiais são desenhados para a familiarização do futuro intercambista com a universidade de destino, cada instituição adapta para a sua realidade os materiais de base do CEPI (no caso do PLA, os materiais de base são os da UFRGS, e no caso do espanhol como língua adicional, são os da Universidade Nacional de Córdoba/UNC, na Argentina) (BULLA et al, 2009). 
Assim, o CEPI UFRGS se propõe a ensinar PLA para os intercambistas falantes de espanhol que farão mobilidade acadêmica para a UFRGS; já no caso das universidades que participaram da concepção e criação do CEPI em conjunto com a UFRGS, quais sejam, UNC e Universidade Nacional de Entre Rios (UNER), também argentina, seus CEPI ensinam espanhol para falantes de português que realizarão intercâmbio na UNC e na UNER, respectivamente (GARGIULO et al, 2009).

O curso tem como objetivos principais iniciar a experiência de intercâmbio dos alunos antes que se dê o deslocamento geográfico, por isso é geralmente realizado em duas edições por ano antes dos semestres letivos das universidades: uma em janeiro e fevereiro, e outra em junho e julho. Também objetiva desenvolver as capacidades linguísticas e culturais em PLA dos estudantes que farão intercâmbio na UFRGS no semestre seguinte ao da participação no CEPI. Sendo assim, o curso propicia um espaço virtual de ensino e aprendizagem de PLA para fins de intercâmbio visando à qualificação da mobilidade acadêmica entre universidades do Mercosul (SCHLATTER et al, 2007). Ao mesmo tempo, o CEPI também se configura, desde sua primeira edição, em janeiro de 2011, como uma oportunidade de formação de professores de PLA para atuação tanto a distância, quanto presencial (SCHLATTER et al, 2009; BULLA; TIMBONI, 2017).

O ensino de PLA no CEPI é baseado na construção conjunta de aprendizagem (VYGOTSKY, 1984; ABELEDO, 2008) entre os participantes do curso a fim de proporcionar práticas sociais de uso da linguagem (CLARK, 2000) em português organizadas por gêneros do discurso (BAKHTIN, 2003). Conforme discutido em Schlatter et al (2009) e Bulla (2014), o CEPI é um curso online organizado para a construção de uma comunidade colaborativa de aprendizagem, na qual a participação de cada um é ratificada, requerida e relevante para tomadas de decisão conjuntas e compartilhamento de autoria, na qual todos podem pedir e oferecer ajuda, concordar, discordar, ponderar, fazer proposições de encaminhamentos quanto às atividades em curso, ao cronograma de atividades, às produções coletivas, aos objetos de aprendizagem (BULLA, 2007; 2014). Estes pressupostos teóricos são os mesmos do PPE/UFRGS, tornando possível que a formação docente feita para o ensino online pelo CEPI também se torne relevante para a formação e a atuação no ensino presencial no PPE (BULLA; TIMBONI, 2017).

Para discutirmos sobre formação de professores de PLA no CEPI, enfocamos, neste trabalho, dados gerados na $10^{a}$ edição do CEPI UFRGS, que somou 30 horas 
divididas em 6 semanas durante os meses de janeiro e fevereiro de 2017, e foi desenvolvido através de grupo privado no Facebook, e-mail, Google Hangout e Moodle. A Equipe CEPI foi composta por duas graduandas em Letras, que desempenharam o papel de professoras de PLA no CEPI, uma mestranda em Linguística Aplicada, que atuou como tutora das professoras, e uma professora do Instituto de Letras da UFRGS, que atuou como coordenadora pedagógica. As interações nos bastidores também ocorreram a distância, através de Whatsapp, Messenger e Google Hangout. A formação de professores é discutida, portanto, através da análise de atividades pedagógicas realizadas entre professoras e alunos do curso online, bem como de interações por nós vivenciadas nos bastidores, como Equipe CEPI. Nos dados aqui analisados, demonstramos como as participantes dos bastidores aprendem a ensinar e a ser professoras de PLA durante o CEPI, em esforços coletivos para a atualização do construto teórico do curso em práticas docentes.

\section{Formação de professores}

Conforme Schön (2000), Nóvoa (1995) e Pérez Gomes (1995), entendemos que o processo de formação de professores deva partir do próprio local onde o profissional atua, através de estreita articulação entre ação profissional, conhecimento e reflexão sobre e na ação. Sendo assim, o "formar-se está relacionado com o agir na prática" (COSTA, 2003, p. 17).

Nesta direção, Costa (2013) propõe que a formação docente ocorre através de eventos de formação. Um evento de formação, segundo o autor, consiste em "um encontro entre dois ou mais participantes, no qual os propósitos de interação entre eles dizem respeito a resolver uma questão relevante para a sala de aula" (p. 18). Para chegar nesta definição, Costa (2013) investigou a formação de professores realizada em um Instituto Cultural Brasileiro no exterior, onde professores não eram, em sua maioria, formados em licenciatura em Letras. Para a coleta de dados, Costa (2013) realizou uma pesquisa qualitativa de cunho etnográfico, com 22 dias de observação participante em reuniões pedagógicas e intervalos entre as aulas.

Quanto à descrição e análise dos eventos de formação no Instituto Cultural pesquisado, o autor afirma que "todos os eventos partem da necessidade de resolução de problemas emergentes da prática de sala de aula e que tem como meta aprender a ensinar" (p. 95). Os dados mostram que os professores buscam orientação entre si para a 
solução de problemas relativos a como ensinar aspectos gramaticais da língua, como organizar as atividades de sala de aula, como elaborar avaliações e como nortear o ensino para os construtos teóricos do exame de proficiência em PLA do governo brasileiro, o Celpe-Bras, entendido nesse contexto como um direcionador do ensino de PLA.

No Instituto pesquisado, Costa (2013) destaca os diferentes locais onde foram observados eventos de formação para além das reuniões de professores. Encontros não planejados de professores na cozinha ou área de serviço, por exemplo, se desdobravam em interações sobre como solucionar questões de suas práticas docentes. A partir disso, o autor destaca o papel do professor mais experiente nesse processo de formação que está orientado a partir das seguintes ações: 1) apresentar modelos e estratégias de ensino; 2) relatar experiências de sala de aula; 3) responder perguntas sobre questões de sala de aula; 4) oferecer ajuda quando solicitada; e 5) solicitar que se faça alguma ação ou atividade. (COSTA, 2013, p. 111). Essa pesquisa, portanto, corrobora a ideia de que a formação de professores é um processo constante e localizado, e que cada local de trabalho do professor demandará a sua formação específica de atuação do profissional.

\section{A formação de professores no CEPI}

Desde a primeira edição do CEPI UFRGS, em janeiro e fevereiro de 2011, a formação de professores ocorre a distância, pela interação mediada por computador entre, no mínimo, uma orientadora pedagógica e um professor de PLA que atuará como professor do curso online com os alunos de PLA. A orientação recai sobre questões relativas ao ensino de PLA, à educação a distância, ao uso de tecnologias por parte do professor e dos alunos CEPI, ao design educacional, à articulação entre as atividades pedagógicas e os diferentes conteúdos que constituem o CEPI, à gestão do curso (incluindo a gestão das atividades de planejamento do professor, bem como a coordenação das atividades dos alunos do curso por parte do professor), às possibilidades interacionais para a atualização dos pressupostos de uso da linguagem, gêneros do discurso e aprendizagem colaborativa.

Com base em Costa (2013), Lemos (2014) analisa eventos de formação de professores nos bastidores da $4^{\mathrm{a}}$ edição do CEPI UFRGS e resume eventos de formação como "momentos em que o participante aprende a ensinar e a ser professor em um determinado contexto" (p. 5). As análises se centram no diário escrito pelas duas 
professoras da edição que atuaram em docência compartilhada (uma professora estava ministrando o CEPI pela segunda vez, e a outra, pela primeira vez), contendo ainda algumas intervenções da orientadora pedagógica; também foram consideradas algumas interações via chat entre elas.

A partir da análise dos dados, Lemos (2014) identificou temas mais recorrentes nos eventos de formação centralmente realizados via escrita dos diários, a saber: “contato inicial com alunos, comunicação com alunos, organização do curso, avaliação dos alunos, rotinas pedagógicas, plataforma e ferramentas" (p. 112). A autora também enfatiza a relevância da docência compartilhada para a formação das professoras no CEPI, destacando a escrita do diário compartilhado como espaço para acompanharem o andamento do curso e do trabalho de cada professora, para refletirem em conjunto sobre problemas levantados e para, também conjuntamente, construírem soluções.

Buscando relacionar interações realizadas nos bastidores (entre duas professoras inexperientes e duas orientadoras) e ações realizadas pelas professoras e alunos nos ambientes digitais do CEPI, Bulla e Timboni (2017) analisam dados envolvendo o planejamento em conjunto de um enunciado de tarefa para publicação no grupo do Facebook; o uso de textos autênticos no CEPI; e a relevância do curso para a formação de professoras inexperientes. Os dados analisados mostram o percurso de decisões tomadas e construídas coletivamente nos bastidores antes de serem propostas para os alunos do CEPI. Também evidenciam o engajamento das orientadoras em não apenas instruir, mas também alinhar a formação das professoras para os pressupostos teóricos do PPE e fomentar a reflexão na ação. Por fim, no último dado analisado, uma das professoras iniciantes afirma que a experiência de docência a distância e com o apoio dos bastidores lhe deu segurança para tomar decisões, o que não ocorreria no ensino presencial pela sincronia inerente. Conforme mencionado anteriormente, as autoras defendem, então, que o CEPI é um espaço de formação de professores para atuarem tanto no ensino a distância, quanto no ensino presencial.

Bulla e Costa (2017) refletem acerca de atividades colaborativas em eventos de formação de professores, analisando dados em que isso ocorre na modalidade a distância e presencial, de acordo com os pressupostos teóricos que orientam o CEPI (online), e os demais cursos do PPE (presenciais). Conforme os autores, comunidades colaborativas se configuram como espaços de interação entre professores, utilizados para compartilhamento de ideias, dúvidas, experiências ou questões pontuais que podem surgir no decorrer das aulas (presenciais ou online), ou mesmo durante seu 
planejamento. Os autores ressaltam a relevância da interação entre os pares para a reflexão da prática e formação de professores. Segundo Bulla e Costa (2017, p. 235),

[...] oportunidades de interação entre professores são facilitadas pela existência de espaços virtuais (no caso do CEPI) e presenciais (no caso do PPE) de convivência. Contudo, a existência desses espaços não garante que a formação ocorra de modo colaborativo. São as interações sobre certos tópicos, com propósitos compartilhados e vinculados a problemas e dúvidas, discutidos por meio de experiências concretas, que possibilitam momentos de aprendizagem, tanto dos menos experientes como dos mais experientes.

No caso do CEPI, o curso oportuniza um espaço online para que tais interações aconteçam. Discorreremos sobre algumas delas abaixo, analisando os dados selecionados para a pesquisa.

\section{Como o CEPI contribuiu para a formação de professoras iniciantes em PLA?}

Nesta seção, analisamos dois dados selecionados do conjunto gerado na $10^{\mathrm{a}}$ edição do CEPI UFRGS, quais sejam: uma sequência de interação escrita via chat entre professora e tutora nos bastidores, e uma de interação escrita via mural do Facebook entre professores e alunos do CEPI. A seleção dos dados foi feita com o intuito de evidenciar diferentes possibilidades de formação de professores no CEPI a partir dos bastidores e do curso em si; especialmente considerando que as professoras graduandas estavam vivenciando sua primeira experiência com o ensino de PLA e com educação a distância.

Na Figura 1, a seguir, podemos observar parte de uma interação escrita via Messenger, um dos espaços utilizados como bastidores do CEPI. Neste momento do chat, uma das professoras e uma das tutoras discutem sobre um trecho da produção escrita de uma aluna, parte da tarefa de escrita de um e-mail para um ex-intercambista da universidade a fim de tirar dúvidas sobre os trâmites e burocracias referentes ao intercâmbio que fariam na universidade, além de outras dúvidas que surgissem. 
Figura 1: Discussão entre tutora e professora sobre a escrita de um aluno

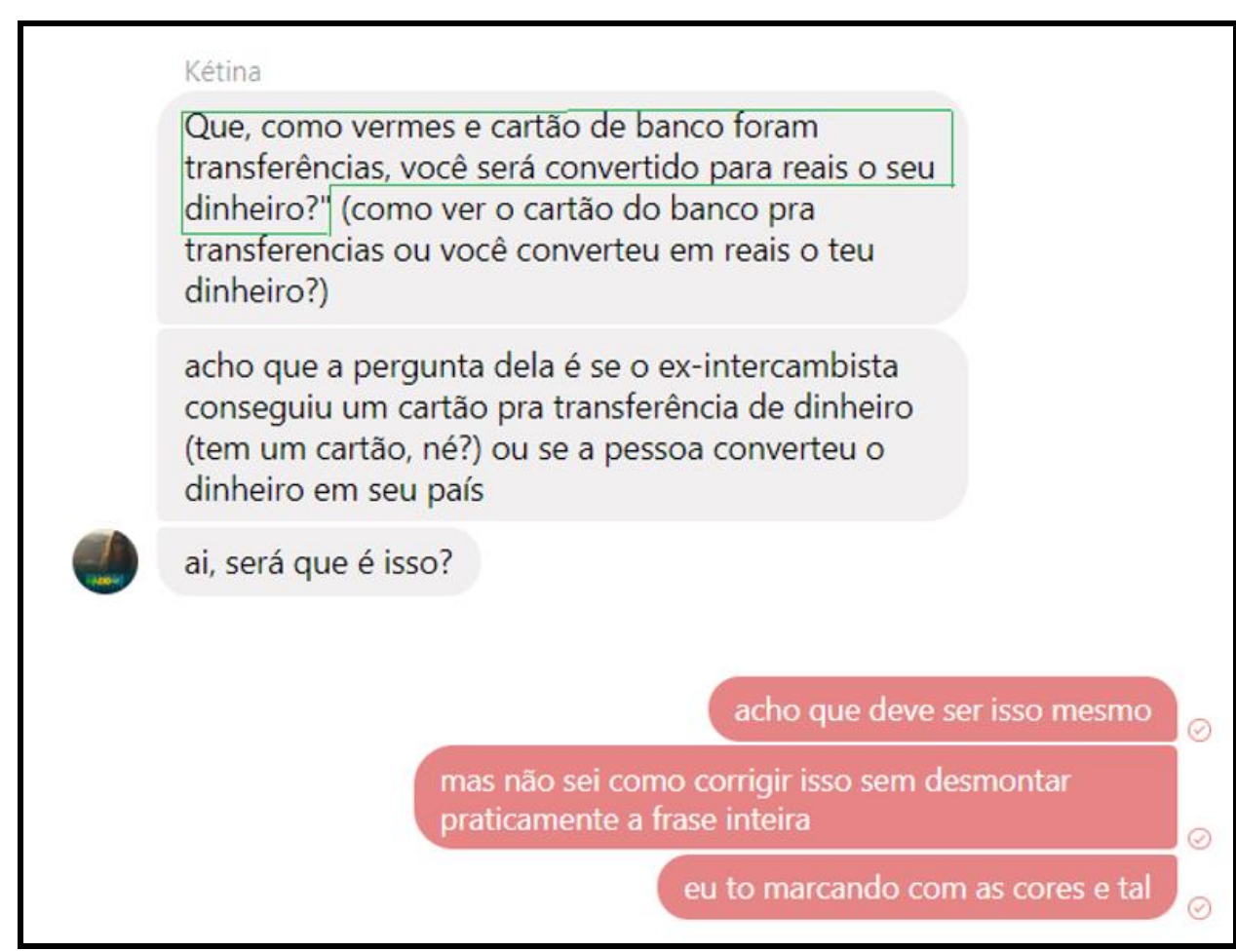

Fonte: Elaborado pelas autoras

O trecho destacado em verde é parte do texto de uma aluna do CEPI que não foi compreendido pela professora que estava corrigindo a tarefa. Após algumas suposições sobre o que a aluna quis dizer com aquela formulação, as mensagens da professora, em rosa, demonstram dúvidas sobre a abordagem do feedback. As mensagens da tutora, em cinza, consistem em sugestões quanto ao método de correção da produção textual, salientando que a questão não é meramente gramatical, mas que deve sim, neste caso específico, focar primeiramente no nível de compreensão, pois não havia sido possível entender a frase da aluna. Na Figura 2, a seguir, observamos a tutora retomando uma referência bibliográfica sugerida à Equipe CEPI nos bastidores. 
Figura 2: Sugestão de correção da tutora

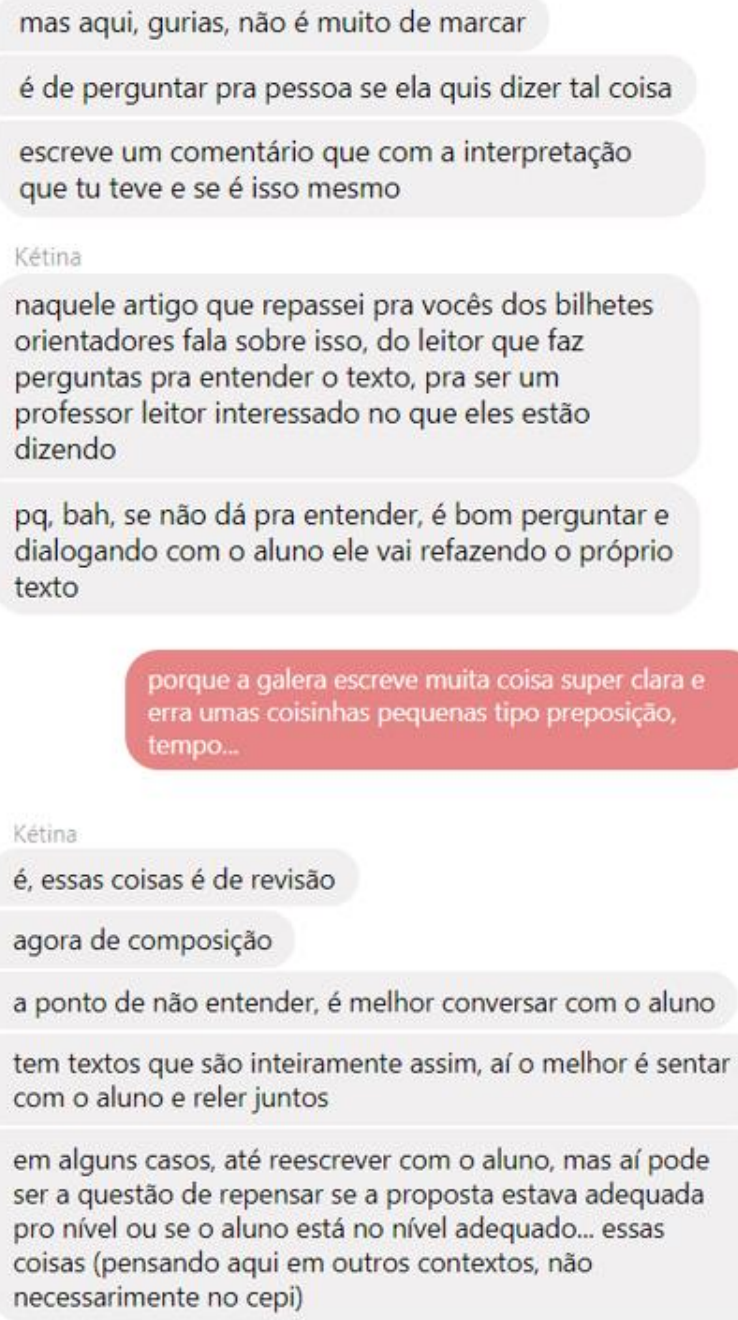

Fonte: Elaborado pelas autoras

Nesse trecho da interação, observamos a articulação entre práticas pedagógicas e pressupostos teóricos que orientam o CEPI, tais como uso da linguagem (CLARK, 2001) e gêneros do discurso (BAKHTIN, 2003). A partir da identificação do gênero do discurso, é necessário pensar no interlocutor do texto (ex-intercambista), no suporte (email), nos propósitos (fazer perguntas sobre a cidade, universidade, burocracias ou curiosidades) e na adequação da linguagem. Dessa forma, no momento em que o professor lê o texto, ele deve considerar a interlocução entre enunciador (aluno do CEPI e futuro intercambista da UFRGS) e interlocutor (ex-intercambista da UFRGS) específicos. Assim, como leitoras interessadas (MANGABEIRA et al, 2011; FARIAS; SIMÕES, 2013), a professora e a tutora leem o e-mail da aluna a fim de verificar a compreensão do texto na prática social projetada pela tarefa, de modo a preparar um 
bilhete orientador que auxilie a aluna na sua reescrita, visando ao cumprimento da tarefa.

Nesse dado (Figuras 1 e 2, anteriores), quando a professora afirma que os alunos escrevem "[...] muita coisa clara e erram umas coisinhas pequenas", evidencia-se também que inadequações de ortografia, sintaxe, seleção lexical eram esperáveis em textos de falantes de espanhol, e que não eram recorrentes até então, no entanto, problemas de compreensão, dado o alto nível de intercompreensão entre falantes de português e de espanhol. Nesse sentido, chamamos atenção para o ponto em que a tutora diz que "são coisas de revisão", tentando contrapor um problema de expressão com questões de revisão, apontando como dois momentos diferentes na correção do texto, o que possui implicações para a produção de feedbacks aos alunos através de bilhetes orientadores.

O próximo dado analisado possui relação com a tarefa "Amigo Secreto", outra atividade pedagógica realizada durante o CEPI. Essa tarefa foi desenhada de forma muito semelhante a um jogo de amigo secreto presencial, porém com adequações para sua implementação a distância. Inicialmente, foi realizado um sorteio do amigo secreto através de um site ${ }^{5}$. Em seguida, os alunos deram dicas a respeito do amigo secreto sorteado, utilizando adjetivos para o cumprimento da tarefa ${ }^{6}$, gerando assim uma brincadeira em que os alunos deveriam adivinhar quem era o amigo sorteado por cada participante do CEPI. Por fim, foi realizada a entrega de "presentes virtuais" que poderiam ser uma imagem, um vídeo do Youtube, uma poesia, uma canção, entre outros. Na Figura 3, a seguir, podemos observar parte da realização desta atividade pedagógica.

${ }^{5}$ Disponível em: https://www.amigosecreto.com.br. Acesso em: 30 jun. 2018.

${ }^{6}$ Os recursos linguísticos necessários para a participação em português nas atividades pedagógicas do CEPI sempre são oferecidos na biblioteca do CEPI no Moodle. Neste caso, por exemplo, a lista de adjetivos já havia sido trabalhada nas apresentações pessoais e, neste momento, o propósito era apresentar o colega por meio de uma brincadeira. 
Figura 3: Presente para a professora

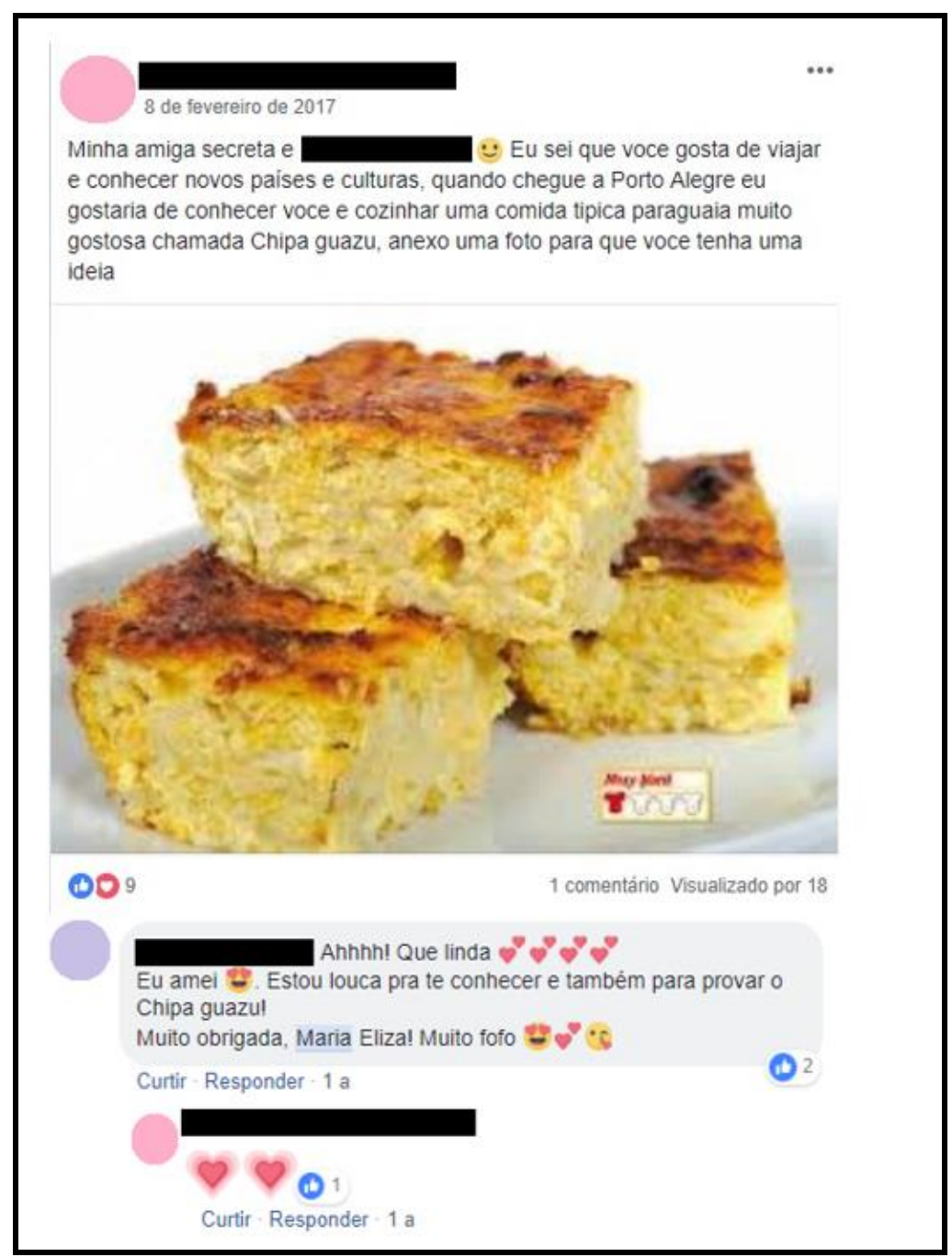

Fonte: Elaborado pelas autoras

Na Figura 3, observamos o momento da entrega de um presente por parte de uma aluna à sua amiga secreta: uma das professoras. De modo bastante resumido, podemos vislumbrar como ocorreu a construção da comunidade colaborativa de aprendizagem online. Nessa direção, pode ser observado como a vivência dessa atividade pedagógica ocorreu de forma horizontal; ou seja, professoras e estudantes ocuparam a mesma posição, participando de modo igualitário das mesmas atividades pedagógicas do curso. Na Figura 4, a seguir, observamos outras interações fomentadas pela tarefa do amigo secreto, porém neste momento a entrega de presentes e revelação do amigo secreto ocorreu entre duas alunas. 
Figura 4: A entrega de presentes entre duas alunas

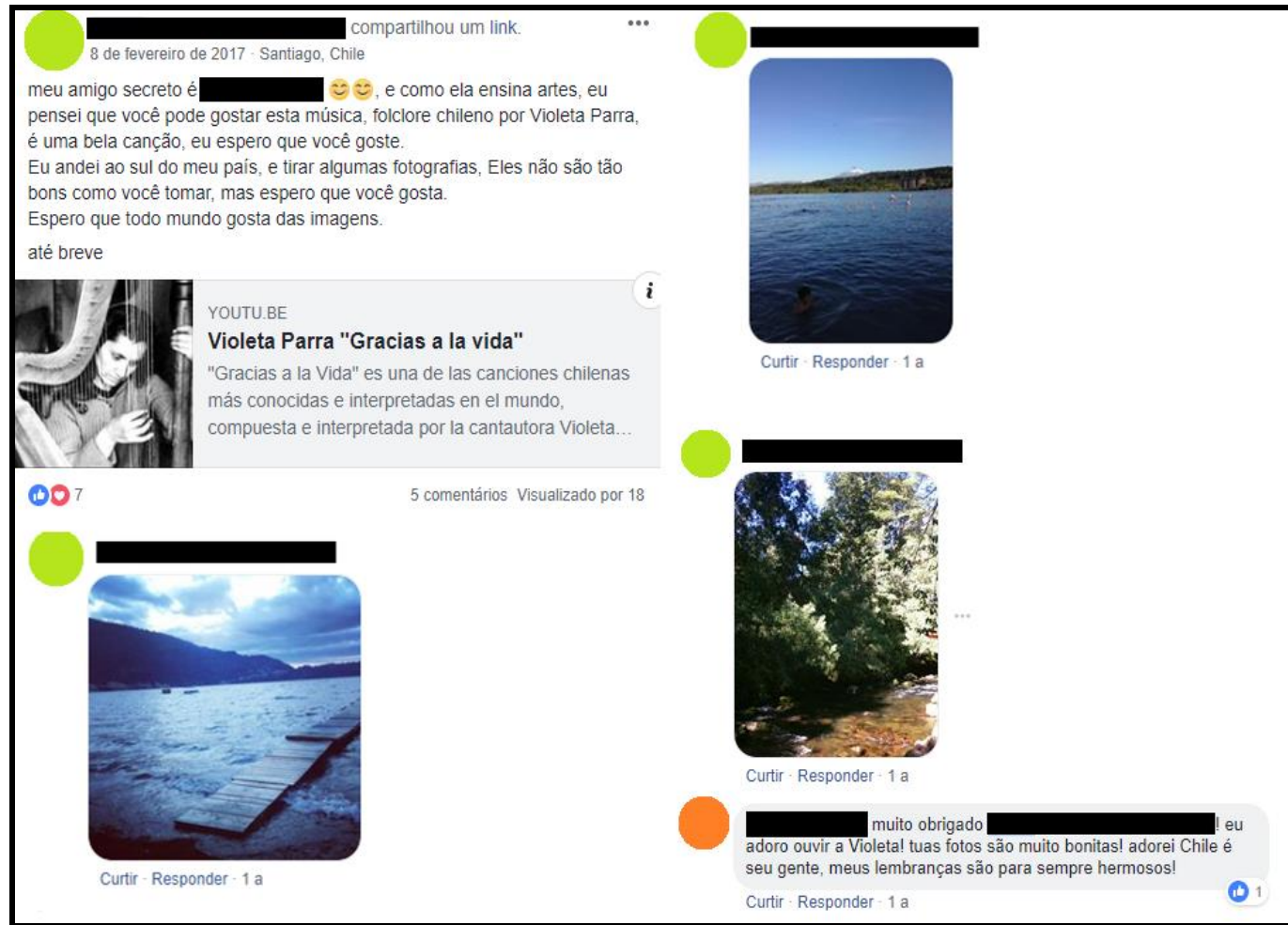

Fonte: Elaborado pelas autoras

Acreditamos que os objetivos educacionais dessa tarefa foram atingidos, pois os alunos se engajaram em interações significativas e espontâneas em português e estreitaram laços importantes para a construção da comunidade online. Também consideramos que a atividade é um exemplo de como em uma única produção é possível se explorar vários gêneros do discurso, com elementos multimodais e hipertextuais típicos da cibercultura.

Entendemos que ambos os dados aqui analisados evidenciam como a formação de professores pode ser alicerçada na reflexão e vivência de modos locais de atualização dos pressupostos teóricos nas práticas pedagógicas. Ademais, reiteram a premissa defendida em Bulla e Costa (2017) acerca da colaboração como princípio tanto para o ensino de PLA, quanto para a formação de professores no PPE.

\section{Considerações finais}

No que diz respeito ao desenvolvimento do curso e prática dos pressupostos teóricos em aula, consideramos que a $10^{\mathrm{a}}$ edição do CEPI foi bem-sucedida. Mesmo tratando-se de impressões pautadas pelas experiências e pontos de vista da equipe 
pedagógica, pensamos que o curso atingiu seus objetivos, uma vez que conseguimos estabelecer interações relevantes com os estudantes, construindo entre docentes e discentes a horizontalidade prevista no CEPI.

Enquanto equipe pedagógica formada por professoras, tutora e coordenadora, destacamos o carácter inovador e desafiador do CEPI para o ensino de PLA. Para as professoras participantes desta edição, o curso foi uma importante experiência de formação docente, pois tratou-se de um ambiente em que as professoras puderam vivenciar uma experiência de sala de aula diferente, que proporcionou tanto o preparo para uma futura atuação presencial quanto o contato com ambientes de ensino e aprendizagem no contexto online.

Também destacamos a importância dessa edição do CEPI para as integrantes da equipe que atuaram na coordenação e tutoria do curso, uma vez que a falta de experiência com PLA e educação a distância por parte das professoras demandou o constante resgate dos pressupostos teóricos do CEPI e reflexão conjunta acerca dos modos possíveis de atualização desses pressupostos em práticas pedagógicas online. Ao longo do curso, tornou-se evidente a construção online de duas comunidades colaborativas de aprendizagem: uma entre professoras e alunos do CEPI, e outra entre nós, professoras e orientadoras, nos bastidores.

\section{REFERÊNCIAS}

ABELEDO, M. L. Uma compreensão etnometodológica da aprendizagem de língua estrangeira na fala-em-interação de sala de aula. Tese (Doutorado em Letras) Instituto de Letras, Universidade Federal do Rio Grande do Sul, Porto Alegre, 2008.

BAKHTIN, M. Estética da criação verbal. Trad. Paulo Bezerra. São Paulo: Martins Fontes, 2003.

BULLA, G. S. A realização de atividades pedagógicas colaborativas em sala de aula de português como língua estrangeira. Dissertação (Mestrado em Letras) - Instituto de Letras, Universidade Federal do Rio Grande do Sul, Porto Alegre, 2007.

BULLA, G. S. Relações entre design educacional, atividade e ensino de português como língua adicional em ambientes digitais. Tese (Doutorado em Letras) - Instituto de Letras, Universidade Federal do Rio Grande do Sul, Porto Alegre, 2014.

BULLA, G. S.; GARGIULO, H.; SCHLATTER, M. Organización general de materiales didácticos para la enseñanza online de las lenguas: el caso del Curso de EspañolPortugués para el Intercámbio (CEPI). In: Anais II Jornadas Internacionales de 
Tecnologías Aplicadas a la Enseñanza de Lenguas, 2009, Córdoba. Córdoba: PlasmaMedia, 2009. v. CD. p. 1-12.

BULLA, G. S.; COSTA, E. V. Atividades colaborativas na formação de professores de Português como Língua Adicional no Programa de Português para Estrangeiros da UFRGS. In: Anais VIII Encontro Internacional de Investigadores de Políticas Linguísticas, 2017, Florianópolis. Florianópolis: UFSC e AUGM, 2017. p. 226-236.

BULLA, G. S.; TIMBONI, K. A. S. Quando a educação a distância prepara o professor para a atuação presencial: o caso da formação inicial de duas graduandas através do Curso online de Espanhol e Português para Intercâmbio (CEPI). In: Anais VIII Encontro Internacional de Investigadores de Políticas Linguísticas, 2017, Florianópolis. Florianópolis: UFSC e AUGM, 2017. p. 237-247.

CLARK, H. H. O uso da linguagem. Cadernos de Tradução, n. 9, p. 49-71, 2000.

COSTA, E. V. Práticas de formação de professores de português língua adicional em um instituto cultural brasileiro no exterior. Dissertação (Mestrado em Letras) Instituto de Letras, Universidade Federal do Rio Grande do Sul, Porto Alegre, 2013.

GARGIULO, H.; BULLA, G. S.; SCHLATTER, M. CEPI: Tareas, herramientas y el enfoque accional en el aprendizaje en línea. In: Anais II Jornadas Internacionales de Tecnologías Aplicadas a la Enseñanza de Lenguas, 2009, Córdoba. Córdoba: PlasmaMedia, 2009. v. CD. p. 01-12.

LEMOS, F. C. A formação do professor para o ensino de língua adicional em ambientes digitais com docência compartilhada. Dissertação (Mestrado em Letras) Instituto de Letras, Universidade Federal do Rio Grande do Sul, Porto Alegre, 2014.

MANGABEIRA, A. B. A; COSTA, E. V.; SIMÕES, L. J. O bilhete orientador: um gênero discursivo em favor da avaliação de textos nas aulas de língua. Cadernos do IL, Porto Alegre, n. 42, p. 293-307, jun. 2011.

NÓVOA, A. Formação de professores e profissão docente. In: NÓVOA, A. (Org.). Os professores e sua formação. Lisboa: Publicações Dom Quixote, 1995. p. 93-114.

PÉREZ GÓMEZ, A. O pensamento prático do professor: a formação do professor como profissional reflexivo. In: NÓVOA, A. (Org.). Os professores e sua formação. Lisboa: Publicações Dom Quixote, 1995. p. 93-114.

SCHLATTER, M.; BULLA, G. S.; GARGIULO, H.; CARVALHO, S. C. O curso de Espanhol-Português para Intercâmbio (CEPI): Uma ação de política linguística construída colaborativamente pelos participantes. Revista Digital de Políticas Lingüísticas, ano 4, v. 4, p. 111-148, 2012.

SCHLATTER, M.; BULLA, G. S.; GARGIULO, H.; JURIC, V. H. S. La formación del profesor CEPI para interactuar en una comunidad colaborativa de aprendizaje a distancia. In: Anais II Jornadas Internacionales de Tecnologías Aplicadas a la Enseñanza de Lenguas, 2009, Córdoba. Córdoba: PlasmaMedia, 2009. v. CD. p. 0118. 
SCHLATTER, M.; BULLA, G. S.; JURIC, V. S.; HRASTE, M.; RODRÍGUES, M. L. A. Certificação Espanhol/Português para Intercâmbio (CEPI) como uma ação de política linguística no âmbito do Mercosul. In: Anais III Encuentro Internacional de Investigadores de Políticas Linguísticas, 2007, Córdoba. Córdoba: UNC e AUGM, 2007. p. 59-64.

SCHÖN, D. A. Educando o profissional reflexivo: um novo design para o ensino e a aprendizagem. Porto Alegre: Artmed, 2000.

SIMÕES, L. J.; FARIAS, B. S. De olho na prática: Conversa vai, escrita vem. Na ponta do lápis, ano IX, n. 21, fev. 2013.

VYGOTSKY, L. S. A formação social da mente. São Paulo: Martin.

\section{Como citar este artigo:}

BULLA, Gabriela da Silva.; TIMBONI, Kétina Allen da Silva.; BULEGON, Mariana.; ANDRADE, Raquel Horvath de. Contribuições do curso online de espanhol-português para intercâmbio (CEPI) na formação de professores de português como língua adicional. Rev. EntreLínguas, Araraquara, v. 4, n. 2, p. 236-250, jul./dez., 2018. eISSN: 2447-3529. DOI: 10.29051/rel.unesp.v4.n2.2018.11878

Submetido em: 31/08/2018

Revisões requeridas em: 25/10/2018

Aprovação final em: 15/11/2018 